\title{
Responsabilidade Social Empresarial da Agroindústria Canavieira e Desenvolvimento Local: estudo de caso em Umuarama/PR
}

\section{Business Social Responsability of Sugarcane Agroindustry and Local Development: case study in Umuarama/PR}

\author{
Ester Fernanda da Silva ${ }^{9}$ \\ Thiago Henrique Moreira Goes ${ }^{10}$ \\ Bárbara Françoise Cardoso ${ }^{11}$ \\ Pery Francisco Assis Shikida ${ }^{12}$
}

Artigo recebido em para publicação em ago/2013 e aceito para publicação em set/2013

\begin{abstract}
RESUMO
O objetivo deste trabalho é analisar as ações de Responsabilidade Social Empresarial da Usina Costa Bioenergia, focando o desenvolvimento local em Umuarama. Para tanto, utilizou-se a compilação de pesquisas realizadas com tal intuito e aplicação de questionário para indagar as instituições e organizações relacionadas direta ou indiretamente com a Usina em questão. A partir dos resultados desta pesquisa, conclui-se que a Costa Bioenergia possui ações estratégicas de RSE, enquadrandose no $3^{\circ}$ estágio de RSE para as ações voltadas aos colaboradores e à comunidade, e no $4^{\circ}$ estágio para as ações voltadas ao meio ambiente. Isto é, a Usina possui ações proativas e apresenta aspectos positivos relevantes para o desenvolvimento de Umuarama. Estes elementos podem ser considerados indutores do desenvolvimento, visto que a Usina busca, além das questões quantitativas, promover e alavancar os aspectos qualitativos de seus funcionários e da comunidade do entorno.
\end{abstract}

Palavras-chave: RSE. Agroindústria Canavieira. Desenvolvimento Local.

\section{ABSTRACT}

This paper aims analyze the Business Social Responsibility actions of the Costa Bioenergia Mill, focusing the local development in Umuarama. For this, this article used the compilation of searches already realized and application of questionnaire to ask institutions and organizations related directly or indirectly with the Costa Bioenergia Mill about this issue. The results showed that this Mill has BSR strategic actions and it fits in the $3^{\text {rd }}$ stage to actions for the employees and the community and in the $4^{\text {th }}$ stage to actions for environment, i.e., Costa Bioenergia Mill has proactive actions and relevant positive aspects for the development of Umuarama. These elements can be considerate development inductors, whereas the Mill seeks to promote and increase the quality aspects of its employers and of the community.

Keywords: BSR. Sugarcane Agroindustry. Local development.

\footnotetext{
${ }^{9}$ Graduanda em Ciências Econômicas e Bolsista PIBIC-CNPQ da Universidade Estadual do Oeste do Paraná (UNIOESTE). E-MAIL: ester fern@hotmail.com

10 Mestre em Desenvolvimento Regional e Agronegócio pela UNIOESTE/Toledo. Professor do Colegiado de Administração da Universidade Estadual do Oeste do Paraná (UNIOESTE). E-mail: thiago goes2@hotmail.com

11 Doutoranda em Desenvolvimento Regional e Agronegócio e Bolsista da Coordenação de Aperfeiçoamento de Pessoal de Nível Superior (CAPES) e Fundação Araucária da UNIOESTE/Toledo. E-mail: barbarafcardoso@gmail.com

12 Professor Associado do colegiado de Ciências Econômicas e do Programa de PósGraduação Stricto Sensu em Desenvolvimento Regional e Agronegócio da UNIOESTE/Toledo. EMAIL: peryshikida@hotmail.com
} 


\section{INTRODUÇÃO}

A Responsabilidade Social Empresarial (RSE) consiste em um elemento que tem recebido muita atenção de pesquisadores, empresas e sociedade ao longo do tempo. Esta importância decorre de fatores específicos, tais como a mudança do comportamento do consumidor (incorporação de novas necessidades e exigências diferentes no decorrer dos anos), as mudanças nas regras ambientais, a preocupação com as externalidades sociais e ambientais que derivam das empresas e também a mudança de pensamento de gestores e executivos das empresas (DRUCKER, 1998).

O conceito de RSE passou por uma evolução ao longo do tempo, desde a conceituação de que o termo não era meramente uma ação filantrópica. $O$ contexto evoluiu ao abarcar elementos que são capazes de estabelecer uma inter-relação do conceito de RSE com outros, tais como o marketing, as finanças, a exigências legais e, principalmente, o capital reputacional e as preocupações com a imagem por parte da empresa (MACHADO FILHO, 2006).

Além das preocupações em âmbito empresarial, as ações de RSE passaram a fomentar aspectos muito importantes em uma sociedade. Entre estes aspectos estão a adoção de técnicas de voluntariado para os colaboradores, o que resulta em benefícios para a comunidade. Outro aspecto consiste no direcionamento de recursos das empresas para ações vinculadas à educação, ao esporte, e à infraestrutura das comunidades do entorno, resultando em melhores condições para a própria comunidade (FISCHER, 2005).

Já em relação à RSE na agroindústria canavieira, é possível identificar que doações e ações sociais visando à comunidade são ações muito comuns para o setor. Além destes aspectos, as proposições sustentáveis do setor constituem um elemento relevante, visto que o setor se caracteriza pela produção de um elemento que pode substituir combustíveis fósseis como matriz energética dominante sem perda de qualidade. Outros fatores relevantes consistem na adoção mais frequente de ações de RSE a partir das certificações internacionais, que são cada vez mais prementes (SOUSA; MACEDO, 2010). 
O município de Umuarama/PR, local do objeto deste estudo, possui uma única usina de cana ${ }^{13}$, Costa Bioenergia, que atua como uma importante empregadora de mão de obra do município sendo uma das usinas do setor mais moderna do Paraná. Além disso, para esta Usina, a RSE tem se tornado um elemento importante, tanto para atender aos mercados internacionais quanto para desenvolver a comunidade ao seu entorno (GOES et al., 2012).

Diante deste contexto e da importância da Usina Costa Bioenergia para o setor sucroalcooleiro no Paraná, esta pesquisa buscou analisar as ações de RSE desta Usina, focando o desenvolvimento local em Umuarama.

O trabalho está estruturado em cinco seções incluindo esta introdução. $\mathrm{Na}$ segunda seção expõe-se o referencial teórico sobre RSE e desenvolvimento local. $\mathrm{Na}$ terceira seção apresenta-se a metodologia utilizada, descrevendo o objeto de estudo e o município onde ele se encontra. Na quarta seção encontra-se a discussão dos resultados. E, por fim, na quinta seção apresenta-se a conclusão deste.

\section{REFERENCIAL TEÓRICO}

\section{Responsabilidade Social Empresarial - RSE}

Bowen (1957) afirma que os empresários deveriam agir de acordo com os interesses da sociedade, visto que desta são extraídos os recursos materiais e financeiros para a continuidade das organizações. Além disso, o autor considera que as organizações são centros de poder que influenciam de diversas formas os indivíduos. Outros autores avançaram nestes conceitos que expõem os novos ideais da RSE, tais como Orlitzky et al. (2011), e colocam as ações sociais como uma forma de ganhos competitivos.

A definição básica de RSE do Instituto Ethos (2011) afirma que ela

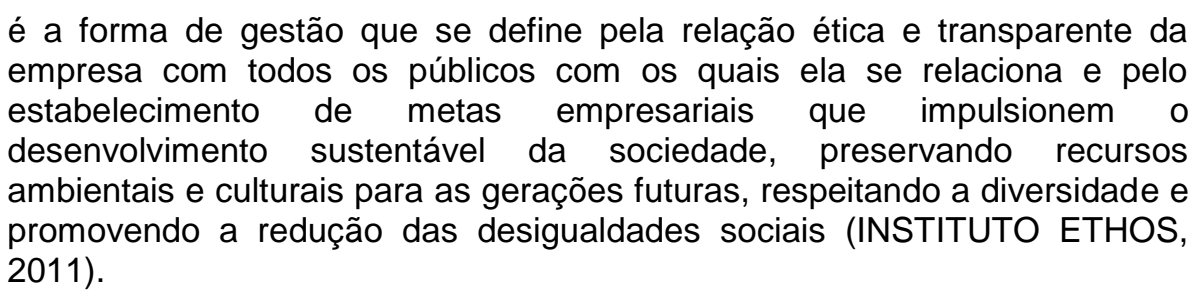

${ }^{13}$ A Usina Costa Bioenergia possui destilaria anexa, por isso, neste trabalho, quando se referir a tal Usina será utilizado apenas o termo usina. 
Este pensamento sobre a relação ética e transparente com os diversos públicos foi estudado anteriormente por Carroll (1991), quando formulou o conceito da pirâmide das responsabilidades sociais corporativas. Esta pirâmide consiste na união de quatro grandes responsabilidades dos "homens de negócios". A primeira versa sobre as responsabilidades junto aos seus acionistas, o que reflete diretamente em responsabilidade pela sobrevivência no mercado. A segunda advém das responsabilidades legais, ou seja, o respeito por parte da organização para o arcabouço legal vigente. A terceira aborda as responsabilidades éticas da organização. Por fim, a última considera as responsabilidades filantrópicas da organização junto aos seus stakeholders. Portanto, a RSE consiste em um ambiente muito mais amplo do que somente as ações filantrópicas da organização.

Jensen (2001) e Sternberg (1999) mantém uma postura crítica quanto às ações de RSE, afirmando que as ações relacionadas aos stakeholders podem prejudicar o objetivo principal da empresa, que é a obtenção de lucros. Todavia não colocam somente como uma questão negativa, visto que estas ações podem servir estrategicamente para as organizações no processo de busca de valor (valueseeking). Destarte, alguns trade-offs podem ser aceitos para que sejam beneficiados os stakeholders das organizações.

Deve-se ressaltar que apesar da complexidade e modelo conflitante encontrado nas relações entre as organizações e seus stakeholders, as organizações estão valorizando o fomento do desenvolvimento interno e externo, bem como adotando práticas sustentáveis em busca da maximização de seu valor (JENSEN, 2001; MACHADO FILHO; ZILBERSZTAJN, 2004).

Machado Filho e Zylbersztajn (2004) sugerem que as organizações podem agir em três níveis: a) internalizando a atividade social; b) criando uma estrutura própria especializada em atividades sociais; e c) promovendo ações sociais por meio de parcerias com outras organizações. No contexto brasileiro, grande parte das práticas de RSE vinculava-se usualmente aos aspectos relacionados à assistência social, alimentação, saúde e educação. Todavia, com o passar do tempo, outras ações alcançaram importância, como o desenvolvimento comunitário, o auxílio à cultura, os incentivos às atividades de lazer, os incentivos à qualificação profissional, desenvolvimento de atividades esportivas, desenvolvimento rural, desenvolvimento urbano e segurança (PELIANO, 2001). 
Complementando estas assertivas, existe ainda uma concepção de grau de profundidade, que está baseada em quatro estágios evolutivos das práticas de RSE exercidas pelas empresas. No primeiro estágio, a empresa ainda se encontra em nível reativo às exigências legais. Posteriormente, no estágio intermediário, ela mantém uma postura defensiva sobre os temas, mas já apresenta indícios de mudanças e avanços em relação à conformidade de suas práticas. Em seguida, no estágio avançado de ações, já são reconhecidos os benefícios de ir além da conformidade legal, preparando-se para novas pressões regulamentadoras do mercado e da sociedade. Por fim, no estágio proativo a empresa atinge padrões considerados de excelência em suas práticas, envolvendo fornecedores, consumidores, clientes, comunidade e também influenciando políticas públicas de interesse da sociedade (INSTITUTO ETHOS, 2007).

Em relação à RSE no agronegócio brasileiro, é possível ressaltar que existem grandes oportunidades na execução dessas ações. Sobre isto, Verdolin e Alves (2005) afirmam que as ações de RSE podem acarretar: a) salvaguardas para que as empresas deste setor afrontem barreiras não tarifárias de outros países com os quais têm relações comerciais; b) condições de atender às necessidades e desejos de um público interno que aumenta seu nível de exigência e avidez por processos e produtos sustentáveis; e c) tendência de aumento da eficiência da produtividade, bem como de melhorias de relação e imagem da organização perante seus stakeholders.

\section{Desenvolvimento Local}

O desenvolvimento econômico, segundo Bresser-Pereira (2008), diferencia-se de crescimento econômico no que tange seu foco, visto que o crescimento decorre do aumento de renda per capita enquanto o desenvolvimento refere-se ao modo como sua distribuição ocorre perante a população. Contudo, o desenvolvimento não decorre somente a partir das técnicas de distribuição de renda, mas também a partir das modificações (e conquistas da sociedade), a forma como a sociedade se comporta, as questões políticas, culturais, ambientais, entre outras.

O desenvolvimento regional, por sua vez, teve seus estudos iniciados após a Segunda Guerra Mundial e foram conduzidos por Perroux, Hirschman e Myrdal. Para tais autores se faziam necessárias teorias que explicassem os desníveis 
encontrados entre regiões, e para tanto introduziram conceitos como pólos de crescimento, renda regional e multiplicadores regionais (AMARAL FILHO, 1996).

Elementos que tendem a fortalecer as regiões economicamente e, consequentemente, agregar desenvolvimento regional às mesmas foram descritos por Boisier (1989):

- participação relativa no uso dos recursos nacionais (recursos financeiros controlados pelo poder público) sobre os quais existe competição entre regiões;

- efeitos regionais implícitos ou indiretos de políticas econômicas macroeconômicas setoriais; e

- desenvolvimento de um conjunto de elementos políticos, institucionais e sociais que elevem a "capacidade de organização da região".

Esta compilação de aspectos relativos ao desenvolvimento econômico e ao desenvolvimento regional funciona como ponte para o desenvolvimento local. Segundo a definição do Institut de Formationen Développement Communautaire IFDEC, o desenvolvimento local é a estratégia de intervenção socioeconômica através da qual os representantes locais do setor privado, público ou social trabalham para valorizar os recursos humanos, técnicos e financeiros de uma coletividade. Além disso, estes atores podem muitas vezes associar-se entre agentes do mesmo setor ou com modelos intersetoriais (com atuantes públicos e/ou privados) com o objetivo central de crescimento da economia local (MARTINELLI; JOYAL, 2004).

O desenvolvimento local, portanto, pode ser caracterizado como um desenvolvimento endógeno, fato que é interpretado por Lima (2006) como o somatório dos recursos locais e da maior participação da comunidade, o que tende a gerar resultados positivos (desenvolvimento) para a sociedade (comunidade local).

A teoria do desenvolvimento local também é partilhada por Martinelli e Joyal (2004) que a definem como o resultado das ações dos atores locais visando maximizar as características produtivas e suprir as necessidades da população. 


\section{METODOLOGIA}

\section{Descrição do Objeto de Estudo e Contextualização}

O objeto de estudo consiste em uma organização da agroindústria canavieira, a Usina Costa Bioenergia em Umuarama-PR, e sua relação com a comunidade do entorno. Para justificar esta escolha metodológica, faz-se necessário descrever brevemente tanto o setor sucroalcooleiro quanto o município e a Usina em questão.

A cana-de-açúcar consiste em uma biomassa capaz de ser transformada em energia e possui características ambientais vantajosas, tais como: ser uma fonte renovável, sua atuação sobre o efeito estufa pode ser equilibrado, e permite o aproveitamento de resíduos para cogeração de energia. Estes fatores, aliados aos maiores controles quanto às emissões de gás carbônico (derivado das queimadas), às novas tecnologias implantadas pela agroindústria canavieira para tornar as operações menos nocivas ao meio ambiente e às práticas de responsabilidade social têm acrescentado características socioambientais importantes à agroindústria canavieira no Brasil (NEVES; CONEJERO, 2009).

Cabe destacar que a agroindústria canavieira possui importância tanto ambiental quanto socioeconômica, tais como valor elevado de tributos pagos, grande poder de indução e de geração de empregos, responsável por proporcionar uma fonte energética que gera menor emissão de poluentes, reaproveitamento de energia, adoção de novas técnicas relativas à menor emissão de resíduos sólidos e líquidos entre outros (NEVES; CONEJERO, 2009; SHIKIDA, 2010).

Quanto ao objeto de estudo e sua localização deve-se dizer que a Usina Costa Bioenergia está localizada em Umuarama, na microrregião Noroeste do Paraná. Esta empresa é considerada uma das líderes da região em número de empregos gerados (em média, 1.100 empregos diretos no período de pico de safra).

\section{Descrição da Pesquisa}

Para a realização deste estudo de caso, esta pesquisa baseou-se nas proposições de Carroll (1991), Martinelli e Joyal (2004) e Instituto Ethos (2007). A proposição de Carroll sugere a existência de quatro níveis de RSE das empresas dentro dos quais a Usina em estudo será classificada considerando as ações que 
ela realiza para atender a cada uma destas responsabilidades e às expectativas sobre os resultados futuros destas ações.

A proposta de Martinelli e Joyal (2004) consiste em que o desenvolvimento local é uma condição ocorrida a partir da interação entre agentes públicos, privados e civis de uma localidade. Portanto, inquirir pessoas ligadas ao poder público e aos órgãos representantes da sociedade pode apresentar como a empresa se comporta perante a responsabilidade social e, sobretudo, se o modelo de comportamento socialmente responsável adotado pela empresa pode ser capaz de gerar desenvolvimento para a comunidade.

Já a proposição do Instituto Ethos (2007) avalia a organização das características das ações realizadas, ou seja, se a empresa encontra-se em um nível reativo, que visa ganhos competitivos, ou em nível proativo, mesmo sem a visão de ganhos competitivos. Tal Instituto encontrou características semelhantes que podem ser agrupadas em estágios de RSE, como mostrado no Quadro 01.

\section{Quadro 01 - Estágios de Responsabilidade Social Empresarial}

\begin{tabular}{|l|l|l|}
\hline Grupo de ações & Classificação & Estágios de RSE \\
\hline \multirow{4}{*}{ Voltadas aos colaboradores } & $0,00-1,25$ & $1^{\circ}$ Estágio \\
& $1,26-2,50$ & $2^{\circ}$ Estágio \\
& $2,51-3,75$ & $3^{\circ}$ Estágio \\
& $3,76-5,00$ & $4^{\circ}$ Estágio \\
\hline \multirow{4}{*}{ Relacionadas à comunidade } & $0,00-1,50$ & $1^{\circ}$ Estágio \\
& $1,51-3,00$ & $2^{\circ}$ Estágio \\
& $3,01-4,50$ & $3^{\circ}$ Estágio \\
Voltadas ao meio ambiente & $4,51-6,00$ & $4^{\circ}$ Estágio \\
& $0,00-2,25$ & $1^{\circ}$ Estágio \\
& $2,26-4,50$ & $2^{\circ}$ Estágio \\
& $4,51-6,75$ & $3^{\circ}$ Estágio \\
& $6,76-9,00$ & $4^{\circ}$ Estágio \\
\hline
\end{tabular}

Fonte: Adaptado de Instituto Ethos (2007) e Gepag (2011).

A alocação da organização nos níveis estabelecidos pelo Instituto Ethos (2007) também foi realizada pelo Gepag (2011), Goes (2013) e Goes et al. (2012). Estes estudos apresentam muitos aspectos relativos ao comportamento da organização no tocante às questões suscitadas pela RSE e a relação da empresa com os demais agentes. 
Sendo assim, consideraram-se estes últimos estudos supracitados para levantar as características das ações de RSE desenvolvidas pela Usina Costa Bioenergia, caracterizando parte deste estudo como uma pesquisa bibliográfica. Para complemento da análise, foi aplicado um questionário para os agentes relacionados, direta e indiretamente, com a Usina em estudo. Este questionário foi enviado para seis agentes, sendo eles: Sindicato Rural, Secretaria de Agricultura e Meio Ambiente, Secretaria de Bem Estar Social, Secretaria de Planejamento, Secretaria de Indústria e Comércio e Sindicato dos Trabalhadores Rurais. No entanto, obteve-se retorno somente do Sindicato Rural e da Secretaria de Agricultura e Meio Ambiente, o que equivale a $30 \%$ dos respondentes potenciais.

\section{RESULTADOS E DISCUSSÃO}

\section{Classificação da Usina Quanto aos Estágios de RSE}

Inicialmente, as ações voltadas aos colaboradores (funcionários da Usina Costa Bioenergia), por exemplo, focalizam a adoção de parcerias com outras instituições para a capacitação destes colaboradores; a minimização de atitudes discriminatórias; a adaptação às novas normas regulamentadoras da atividade funcional; e a realocação de trabalhadores em outras atividades dentro da empresa, pois tem ocorrido grande avanço do percentual de colheita mecanizada para o setor no Paraná.

De acordo com Gepag (2011), tem-se que a Usina Costa Bioenergia possui uma estrutura relevante de ações voltadas aos colaboradores. O conjunto dessas ações consiste em: existência de planos de carreira dentro das empresas do setor sucroalcooleiro paranaense; adoção de práticas que visem à minimização e eliminação de atitudes discriminatórias (seja no momento da contratação seja no ambiente de trabalho); consulta aos trabalhadores sobre questões importantes da atividade da empresa; existência de planos de saúde, segurança e apoio social aos colaboradores; adoção de medidas, por parte da empresa, que possam proporcionar aos colaboradores equilíbrio entre a vida profissional e pessoal. Para este conjunto de ações, a Usina Costa Bioenergia está situada no $3^{\circ}$ estágio da RSE de acordo com a classificação do Instituto Ethos (2007). 
Cotejando os resultados destas e de outras pesquisas com afirmações relacionadas à temática da RSE, bem como com a do desenvolvimento local podese destacar algumas contribuições da Usina analisada para a comunidade. Fischer (2005), por exemplo, considera que as ações envolvendo os colaboradores estão entre as mais utilizadas na temática da responsabilidade social, sobretudo após a percepção da interação entre as ferramentas de gestão de pessoas e dos pressupostos da RSE. Quanto ao desenvolvimento local, entende-se que o ideal de desenvolvimento perpassa tanto pelas condições econômicas quanto sociais, portanto a partir do momento em que as empresas, neste caso, as usinas, buscam proporcionar melhores condições sociais aos seus colaboradores, pode-se afirmar que estão colaborando para o desenvolvimento local.

Em relação às ações voltadas à comunidade, as principais diretrizes da Usina Costa Bioenergia estão voltadas ao auxílio em questões de infraestrutura para distritos nos quais possui produção de matéria-prima (como utilização de cascalho em vias de difícil acesso); participação dos colaboradores em campanhas de doação de sangue; projetos visando a inserção dos filhos (jovens e adolescentes) dos funcionários no mercado de trabalho, mediante cursos técnicos e/ou profissionalizantes (GOES et al., 2012).

Comparando a pesquisa de Goes et al. (2012) com a do Gepag (2011), encontra-se similaridades nas ações da Costa Bioenergia, visto que para o conjunto de ações visando a comunidade, a Usina também obtém resultados positivos. De acordo com Gepag (2011), os itens que compõem o conjunto de ações relativas à comunidade são: disponibilidade de vagas de empregos e estágios para jovens; disponibilidade de vagas de emprego para pessoas pertencentes a grupos menos favorecidos; realização de diálogos com a comunidade sobre questões importantes ou delicadas, como destinação de resíduos; realização de aquisições no mercado local; incentivos a ações de voluntariado dos colaboradores na comunidade; e disponibilidade de apoio financeiro para a comunidade. Para este conjunto de ações, a Usina Costa Bioenergia foi alçada novamente ao $3^{0}$ estágio, ou seja, possui práticas proativas de RSE voltadas à comunidade.

O último item contemplado sobre as ações de RSE corresponde às ações voltadas ao meio ambiente. As principais ações realizadas pela Usina neste segmento estão atreladas a três grandes conjuntos: o primeiro está relacionado ao 
controle de emissões de poluentes atmosféricos; o segundo, ao controle dos resíduos sólidos; e o terceiro conjunto, por sua vez, é dedicado ao controle da qualidade dos efluentes. Algumas ações pontuais presentes entre esses conjuntos podem ser mencionadas, tais como: respeito às normas específicas para caldeiras; parcerias junto à Associação dos Produtores de Bioenergia do Estado do Paraná (ALCOPAR), Instituto Ambiental do Paraná (IAP) e outros grupos setoriais para a adoção de normas regulamentadoras da questão ambiental; e implantação de medidas para minimizar o consumo de energia (GOES et al., 2012).

É também perceptível que a Usina Costa Bioenergia também possui níveis elevados de ações ligadas à questão ambiental. Os itens que compõem o conjunto de ações relativas ao meio ambiente são: redução do impacto ambiental em termos de economia de energia; diminuição dos custos operacionais ao reduzir este tipo de impacto; mensuração de impactos ambientais ao desenvolver novos produtos e serviços; disponibilidade de informações aos stakeholders sobre os impactos ambientais causados pelos produtos e serviços disponibilizados pela empresa; e identificação de vantagens sobre as concorrentes a partir de ações sustentáveis. Tais ações alçaram a Usina ao 4ำ nível da RSE para ações voltadas ao meio ambiente. Isto sugere que a Usina é, além de proativa, elemento de mudança quanto à RSE.

\section{Ações de RSE da Usina Costa Bioenergia}

De maneira compendiada, algumas considerações importantes devem ser expostas para compreender as ações de RSE da Usina Costa Bioenergia, bem como os estágios alcançados. A primeira destas considerações refere-se aos colaboradores. Pode-se afirmar que a comunidade empresarial possui como uma de suas tendências o contínuo investimento de recursos financeiros e não financeiros em ações de RSE destinadas aos colaboradores visando desde a minimização de riscos aos possíveis benefícios que podem derivar do comportamento socialmente responsável (DRUCKER, 1998).

Quanto aos condicionantes das ações de RSE visando a comunidade, poderse-ia analisá-las como uma resposta da Usina Costa Bioenergia aos benefícios concedidos pela comunidade onde está inserida, tais como espaço, localização, mão de obra e, em muitos casos, as matérias-primas para as atividades da Usina. 
Portanto, a Usina assume determinadas responsabilidades para não causar externalidades prejudiciais à comunidade. Além disso, segundo Peliano (2001), as ações voltadas à comunidade refletem o tipo mais comum da RSE e podem estar ligadas ao auxílio à cultura, ao esporte, práticas de assistência social etc.

Os condicionantes das ações ligadas ao meio ambiente estão atrelados às normativas internacionais, aos grupos de pressão, às novas exigências legais entre outros. Estes condicionantes podem ser separados em três conjuntos, sendo que o primeiro deles consiste nas próprias estratégias empresariais, visto que as ações sustentáveis estão entre os focos mais comuns da RSE da Usina. O segundo conjunto está relacionado à pressuposição de dano ambiental causado por outros agentes, tais como grupos de pressão, agentes reguladores entre outros. O terceiro consiste na própria concepção do setor sucroalcooleiro, visto que este setor está caracterizado como produtor de uma commodity que, por si só, possui características sustentáveis, como a produção de etanol.

\section{Visão de Outros Stakeholders sobre a Usina}

Tendo a noção exposta sobre o nível das ações de RSE da Usina Costa Bioenergia em estudo, necessita-se verificar a visão de outros stakeholders do setor sobre os benefícios e malefícios causados pela existência dessa Usina em Umuarama-PR.

Neste contexto, a visão do IAP de Umuarama é que, não somente a Usina Costa Bioenergia, mas também as demais empresas do Estado têm adotado políticas sustentáveis proativas. Isso se deve à substituição parcial da colheita manual pela colheita mecanizada, o que evita o processo de queima do canavial. Quanto aos problemas ambientais, a Usina mostrou-se preocupada com tais questões, não apenas no que se referem as suas atividades, mas também nos outros empreendimentos do grupo que a detém.

$\mathrm{Na}$ visão da ALCOPAR, o primeiro aspecto relevante para a adoção da RSE pela Usina foi a Lei no 4.860 de 1965. Esta lei versava sobre a obrigação das usinas e destilarias em repassar $1 \%$ do valor da produção de cana, $1 \%$ do valor da produção e comercialização do açúcar e $2 \%$ do valor da produção e comercialização do álcool como contrapartida para investimentos em benefícios para a sociedade e para colaboradores. 
Em relação às ações de RSE no âmbito da comunidade do entorno, o representante da mídia especializada afirmou que as usinas e destilarias, inclusive a Usina Costa Bioenergia, buscam manter uma relação próxima com as comunidades onde estão inseridas, pois elas são fonte de recursos humanos, matérias-primas e os conflitos são muitas vezes minimizados a partir destas ações (GOES, 2013).

Para a Secretaria de Agricultura e Meio Ambiente e Sindicato Rural de Umuarama, de acordo com o resultado desta pesquisa, alguns aspectos relevantes sobre a Usina Costa Bioenergia podem ser elencados. Os aspectos positivos destacados foram, basicamente a arrecadação da Usina que é financeiramente positiva para o município, e a geração de empregos, que é importante para o crescimento econômico do mesmo. Entre os aspectos negativos está a questão das queimadas, que ainda causam incômodos às pessoas do entorno, sobretudo às pessoas que moram em andares mais altos dos prédios de Umuarama. Estas pessoas comumente reclamam de problemas causados pela falta da mecanização total da colheita da cana. Outro aspecto negativo consiste na concentração fundiária proporcionada por um agente com quantidade vultuosa de recursos. Outrossim, a Secretaria de Agricultura e Meio Ambiente afirmou que a Usina Costa Bioenergia participa ativamente dos processos de melhoria da comunidade.

\section{CONSIDERAÇÕES FINAIS}

Este trabalho procurou analisar as ações de Responsabilidade Social Empresarial da Usina Costa Bioenergia, focando o desenvolvimento local em Umuarama. Para tanto, utilizou-se a compilação de pesquisas realizadas com tal intuito e aplicação de questionário para indagar as instituições e organizações relacionadas direta ou indiretamente com a Usina em questão.

A partir dos resultados desta pesquisa, pode-se concluir que a Usina possui ações estratégicas de RSE, enquadrando-se no $3^{\circ}$ estágio de RSE para as ações voltadas aos colaboradores e à comunidade, e no $4^{\circ}$ estágio para as ações voltadas ao meio ambiente. Isto é, a Costa Bioenergia possui ações proativas.

Tais ações visam o acréscimo de bem estar não somente para os colaboradores, mas também para a comunidade. Essas ações podem ser sumarizadas através do oferecimento de alguns serviços básicos, tais como fornecer plano de saúde aos colaboradores e suas famílias, demandar mão de obra do 
município e reduzir as queimadas. Esta última ação também é percebida como ações voltadas ao meio ambiente, pois além de melhorar a qualidade do ar para os moradores, reduz a poluição ambiental. Como elemento negativo, cabe citar a não mecanização total da colheita de cana e a concentração fundiária supracitadas.

Por fim, pode-se afirmar que a Usina Costa Bioenergia apresenta aspectos positivos relevantes para o desenvolvimento de Umuarama. Estes elementos podem ser considerados indutores do desenvolvimento, visto que a Usina busca, além das questões quantitativas, promover e alavancar os aspectos qualitativos de seus funcionários e da comunidade do entorno.

\section{REFERÊNCIAS}

AMARAL FILHO, J. Desenvolvimento regional endógeno em um ambiente federalista. Planejamento e políticas públicas. Revista Pesquisa e Planejamento Econômico. Brasília: IPEA, n.14, p.35-73, dez. 1996.

BOISIER, S. Política econômica, organização social e desenvolvimento regional. In: HADDAD, P. R. (Org.). Economia regional: teorias e métodos de análise. Fortaleza: BNB. ETENE, 1989. p. 589-689.

BOWEN, H. R. Responsabilidades sociais do homem de negócios. Rio de Janeiro: Civilização Brasileira, 1957.

BRESSER-PEREIRA, L. C. Crescimento e desenvolvimento econômico. Notas para uso em curso de Desenvolvimento Econômico na Escola de Economia de São Paulo da Fundação Getúlio Vargas. Versão de junho de 2008. Disponível em <www.bresserpereira.org.br>. Acesso em 10 nov 2012.

CARROLL, A. B. The pyramid of corporate social responsibility: toward the moral management of organizational stakeholders. Business Horizons, Bloomington, v. 34, n. 4, p. 39-48, 1991.

DRUCKER, P. F. Introdução à administração. 3 ed. São Paulo: Pioneira, 1998.

FISCHER, R. M. Estado, mercado e terceiro setor: uma análise conceitual das parcerias intersetoriais. Revista de Administração, São Paulo, v. 40, n. 1, p. 5-18, 2005.

GOES, T. H. M. Estratégias de responsabilidade social empresarial (RSE) na agroindústria canavieira paranaense. $131 \mathrm{f}$. Dissertação (Mestrado em Desenvolvimento Regional e Agronegócio) - Universidade Estadual do Oeste do Paraná, Toledo, 2013.

GOES, T. H. M.; SCHMIDT, C. M.; GIMENES, R. M. T. Estratégias de Responsabilidade Social Empresarial: um estudo de caso em uma usina de açúcar e 
álcool do Paraná. In: 50ํㅜ CONGRESSO BRASILEIRO DE ECONOMIA, ADMINISTRAÇÃO E SOCIOLOGIA RURAL, 2012, Vitória-ES. Anais eletrônicos... Brasília-DF: $\quad$ Sober, $2012 . \quad 18 \quad$ p. Disponível em: $<$ http://icongresso.itarget.com.br/useradm/anais/?clt=ser.2>. Acesso em: 16 nov 2012.

GEPAG. Identificação de práticas de responsabilidade social empresarial em usinas e destilarias paranaenses. Questionário e resultados, UNIPAR Universidade Paranaense, 2011 (impresso).

INSTITUTO ETHOS. Indicadores Ethos de responsabilidade social empresarial 2007. São Paulo: 2007.

INSTITUTO ETHOS. O que é RSE? Disponível em: $<$ http://www1.ethos.org.br/EthosWeb/pt/29/ o que e rse/o que e rse.aspx>. Acesso em: 10 nov 2012.

JENSEN, M. Value Maximization, stakeholder theory and the corporate objective function. Journal of Applied Corporate Finance, New York, v. 14, n. 3, p. 8-21, 2001.

LIMA, A. E. M. A teoria do desenvolvimento regional e o papel do Estado. Análise econômica. Porto Alegre, ano 24, o 45, p. 65-90, mar. 2006.

MACHADO FILHO, C. A. P. Responsabilidade social e governança: o debate e as implicações. São Paulo: Cengage Learning, 2006.

MACHADO FILHO, C. A. P.; ZYLBERSZTAJN, D. A empresa socialmente responsável: o debate e as implicações. Revista de Administração, São Paulo, v. 39, p. 242-254, 2004.

MARTINELLI, D. P.; JOYAL, A. Desenvolvimento local e o papel das pequenas e médias empresas. Barueri: Manole, 2004.

NEVES, M. F.; CONEJERO, M. A. Estratégias para a cana no Brasil: um negócio classe mundial. São Paulo: Atlas, 2009.

ORLITZKY, M.; SIEGEL, D. S.; WALDMAN, D. A. Strategic corporate social responsibility and environmental sustainability. Business and Society, Chicago. v. 50 , n. 1, p. 6-27, 2011.

PELIANO, A. M. T. M. (Coord.). Bondade ou interesse: como e porque as empresas atuam no social. Brasília, DF: IPEA, 2001.

SHIKIDA, P. F. A. Desenvolvimento socioeconômico e agroindústria canavieira no Paraná. Revista de Política Agrícola, Brasília, DF, ano XIX, n. 3, p. 67-82, 2010.

SOUSA, E. L. L.; MACEDO, I. C (coord.). Etanol e bioeletricidade: a cana-deaçúcar no futuro da matriz energética.São Paulo: UNICA, 2010. 
STERNBERG, E. The stakeholder concept: a mistaken doctrine. Leeds: Foundation for Business Responsibilities, 1999. (Issuepaper, 4).

VERDOLIN, D. R.; ALVES, A F. Responsabilidade social: perspectivas para o agronegócio. Organizações rurais e agroindustriais. Lavras, v. 7, n. 1, p. 103-113, 2005. 